\title{
Transferência e Complexo de Édipo, na Obra de Freud: Notas sobre os Destinos da Transferência
}

\author{
Lara Cristina d'Avila Lourenço' \\ Universidade de São Paulo, Ribeirão Preto
}

\begin{abstract}
Resumo
Este artigo comunica algumas considerações sobre o conceito de transferência, na teoria freudiana. Especial atenção é voltada para as relações entre transferência, complexo de Édipo e complexo de castração. Partindo dessas relações e da hipótese segundo a qual Freud não apresenta um final possível para o complexo de Édipo, o presente trabalho entende que esse autor não fornece uma teoria sobre o final da transferência. Esse pensamento evoca o impasse freudiano em relação aos términos das análises. Nesse ponto, é feita uma breve referência à teoria lacaniana sobre a castração e a transferência ao final de análise.
\end{abstract}

Palavras-chave: Transferência; análise; complexo de Édipo; complexo de castração.

Transference and Oedipus Complex, within Freud's Theory: Notes about the Transference Destiny

\begin{abstract}
This article discloses some considerations about the transference conception situated within Freud's theory. The relations between transference, Oedipus complex and castration complex are highlighted. Starting from these relations and from the allegedly in wich Freud doesn't reveal a possible ending to Oedipus complex, this current work perceives that this author does not provide a theory about the transference ending. This idea drives into Freud's impasse, as far as the analysis ending is concerned. In this issue, a short reference is produced on Lacan's castration theory and on that of the transference at end of the analysis.

Keywords: Transference; analysis; Oedipus complex; castration complex.
\end{abstract}

O aparecimento da noção de transferência é concomitante ao surgimento da psicanálise e sua importância é sempre marcada na obra freudiana. Freud nos fala sobre o surgimento e a dinâmica da transferência, bem como sobre o jogo de seduções e embaraços que ela cria ao tratamento. Porém, o que não chega a ser formulado explicitamente nos textos freudianos é uma teoria sobre o desenlace da transferência; ou, melhor dizendo, sobre o que efetivamente ocorre com esse mecanismo psíquico ao final de um processo analítico. Mais que isso: o pensamento freudiano possibilita dúvidas quanto à natureza e à viabilidade de um final de análise.

Os estudos de Freud sobre a transferência são intimamente ligados à teoria sobre o complexo de Édipo (e ao intrínseco conceito de complexo de castração). A transferência é, grosso modo, reedições de conteúdos edípicos. Esse fato é visto, concomitantemente, como obstáculo e facilitador do tratamento. Compartilhando a opinião de D'Avila Lourenço (2000), segundo a qual o complexo de Édipo freudiano não parece ser passível de conclusão pelo indivíduo, este artigo entende que a questão do final da transferência é problemática para Freud.

O presente trabalho destina-se à apresentação dessa problemática relativa à natureza da transferência e ao questionamento de seu estatuto ao final de análise, segundo a obra de Freud. Salientamos que tal problemática só se torna visível devido à coerência e honestidade do pensamento freudiano. Sem a pretensão de ser exaustivo, este estudo atém-se a um recorte bibliográfico que permite apreender a noção de transferência como pivô do processo analítico.

\footnotetext{
${ }^{1}$ Endereço para correspondência: Rua: Campos Sales, 398, 81, 14015 110, Ribeirão Preto, SP. Fone: (16) 625471. E-mail: laracdl@hotmail.com
}

\section{A transferência e o surgimento da psicanálise}

Durante o início de seus estudos sobre as neuroses, Freud mantém uma parceria intelectual com Breuer, com quem escreve Estudos sobre a histeria, publicado em 1895. O então parceiro de Freud comunica-lhe o caso de uma paciente tratada sob o método hipnótico. Trata-se de Bertha Pappenheim, que na descricão do caso é denominada Anna O., cujo tratamento é encerrado precocemente por Breuer. De acordo com Freud, o encerramento precoce do caso acontece devido ao choque produzido, no médico, pela manifestação da transferência da paciente. Diante dos efeitos que a transferência e a contratransferência produzem até mesmo em sua vida privada, Breuer, alarmado, abandona o caso e dá a paciente por curada. Mediante tal decisão do médico, essa paciente apresenta uma gravidez nervosa, ou seja, diante do impacto suscitado pela interrupção abrupta do tratamento, ela reage com a produção de um sintoma neurótico (pseudociese). A partir do relato de Breuer, Freud começa a perceber que existe uma relação entre a sintomatologia produzida e o rompimento prematuro do vínculo afetivo entre essa paciente e seu médico. Portanto, fica entendido que a intervenção do médico tem a capacidade de influenciar, alterar ou até mesmo produzir novos sintomas.

Com isso, começam a surgir idéias que se tornarão presentes ao longo da obra de Freud, tais como: a transferência, cujo conteúdo é sempre sexual, não é peculiar a um ou outro tratamento, mas à própria neurose; o sentimento transferencial encontra-se pronto, por antecipação, só aguardando a oportunidade de dirigir-se à figura do médico, a qual, por sua vez, ocupa na transferência o lugar de algum personagem importante na história do paciente.

Segundo Freud, em A dinâmica da transferência (1912/1980), a junção da disposição inata com os acidentes da história individual 
faz com que o sujeito adquira uma forma específica de conduzirse na vida erótica. Ele adquire aquilo que o autor denomina clichê estereotípico, o qual é constantemente repetido no decorrer de sua vida, sem que exista consciência dessa reedição de padrões de relacionamento. $\mathrm{Na}$ neurose, há uma fixação ainda maior nesses protótipos afetivos. $\mathrm{E}$ é dessa forma que o indivíduo dirige-se ao médico.

A partir da visão da importância da figura do analista para o tratamento, Freud nunca perde o referencial da transferência na direção de suas descobertas teóricas. A insistência do amor de transferência pode ser considerada propulsora da técnica analítica. Assim Anna O., em sua tentativa de sedução, faz manifestar seu desejo de ser ouvida. Com isso, ela é a primeira paciente a demonstrar os efeitos da chamada talking cure, ou seja, ela demonstra que a fala (e não somente a repetição dramática dos acontecimentos traumáticos) leva a resultados terapêuticos. Contudo, essa paciente ainda é tratada sob o método hipnótico. Não tarda, porém, para que Freud prescinda dos recursos da hipnose na condução de sua prática clínica.

Abandonada a técnica da hipnose, a importância no tratamento é concedida à resistência do paciente. A ênfase passa a recair sobre os mecanismos de exclusão de conteúdos psíquicos da consciência, isto é, sobre aquilo que Freud, em História do Movimento Psicanalítico (1914/ 1980), considera a pedra angular sobre a qual repousa toda a estrutura da psicanálise: o recalque (Die Verdrängung). Trata-se então de preencher as lacunas da memória do paciente, ou seja, superar suas resistências advindas do recalque.

Aprofundando suas pesquisas em torno do funcionamento dos conteúdos recalcados, em Recordar, repetir e elaborar (1914/ 1980), Freud nos diz que aquilo que o paciente resiste em recordar é expresso pela atuação. Durante o tratamento, o paciente não pode se livrar disso que o autor denomina compulsão à repetição. Mas qual a relação dessa compulsão à repetição com a transferência e com a resistência? Freud declara:

Logo percebemos que a transferência é, ela própria, apenas um fragmento da repetição e que a repetição é uma transferência do passado esquecido, não apenas para a figura do médico, mas também para todos os outros aspectos da situação atual. (Freud, 1912/1980, p. 197)

E sobre a relação da transferência com a resistência, nosso autor aborda o uso, feito pelo paciente, das idéias transferenciais. Esse uso torna-se mais sistemático quando, no decorrer da análise, as deformações do material patogênico começam a ser insuficientes à medida em que vão sendo desvendadas pelas interpretações do médico:

Inferimos desta experiência que a idéia transferencial penetrou na consciência à frente de quaisquer outras associações possíveis, porque ela satisfaz a resistência... Reiteradamente, quando nos aproximamos de um complexo patogênico, a parte desse complexo capaz de transferência é empurrada em primeiro lugar para a consciência e defendida com a maior obstinação. (Freud, 1912/1980, p. 138)

Mas isso não leva a crer que a transferência seja exclusivamente um obstáculo ao tratamento e que, portanto, deva ou possa ser eliminada do mesmo. Ao contrário, esse mecanismo psíquico é um indicador da direção do processo analítico. É um facilitador que exige o posicionamento preciso da figura do analista. De posse dos dados fornecidos pela compulsão à repetição, o analista deve manejar a transferência para que o paciente deixe de ficar somente repetindo seus sintomas e comece a prestar atenção às suas queixas, isto é, a considerar que seus sintomas são dignos de uma investigação ativa. O paciente deve então se entregar à tarefa de recordar. Contudo, observamos com Freud que alguns pacientes firmam-se, exageradamente, nessa compulsão à repetição e abandonam o tratamento antes que a transferência seja manejada.

O manejo da transferência consiste, num primeiro momento, em que o analista permita ao paciente atuar exclusivamente na transferência:

Tornamos a compulsão inócua, e na verdade útil, concedendo-lhe o direito de afirmar-se num campo definido. Admitimo-la à transferência como a um playground no qual lhe é permitido expandirse em liberdade quase completa e no qual se espera que nos apresente tudo no tocante à pulsões patogênicas, que se acha oculto na mente do paciente. Contanto que o paciente apresente complacência bastante para respeitar as condições necessárias da análise, alcançamos normalmente sucesso em fornecer a todos os sintomas da moléstia um novo significado transferencial e em substituir sua neurose comum por uma neurose de transferência, da qual pode ser curado pelo trabalho terapêutico. (Freud, 1914/1980, p. 201)

Assim a estratégia traçada por Freud é bem definida: o tratamento deve proporcionar os meios que facilitem a transferência dos conteúdos patogênicos da neurose para os limites definidos pelo enquadre analítico, no qual o analista posiciona-se de modo a atrair esses conteúdos que se deslocam sobre sua figura. Isso faz da cena analítica o palco privilegiado de manifestações dos conflitos intrapsíquicos do paciente.

\section{Gênese edípica da transferência}

Embora no artigo Fragmentos da análise de um caso de bisteria (Freud,1905/1980) a expressão complexo de Édipo não apareça formalmente no texto, há o interesse do autor pelas circunstâncias familiares da paciente, com o intuito não só de verificar os componentes hereditários da doença, mas principalmente de analisar a importância dos vínculos afetivos envolvidos na manifestação da neurose. Esse caso clínico, mais conhecido na literatura psicanalítica como Caso Dora, é particularmente decisivo para a análise do complexo de Édipo. Pois, nele Freud tem condições de avaliar as interferências, ou talvez fosse melhor dizer, o determinismo do complexo de Édipo no processo da transferência (D’ Ávila Lourenço, 2000). E assim, a compreensão do fenômeno da transferência ganha novos contornos.

Freud conduz esse caso clínico a partir dos pressupostos sobre a sexualidade neurótica e da idéia de que a relação transferencial da paciente é marcada por uma repetição de suas relações arcaicas com a figura paterna. Vale lembrar os engodos, confessos por Freud, envolvidos na análise da transferência desse caso clínico. É particularmente interessante o fato de que a interpretação mal sucedida 
da transferência de Dora leva Freud às noções de bissexualidade do complexo de Édipo e de ambivalência inerente ao sentimento transferencial. Além disso, os impasses desse caso clínico encaminham o autor à percepção das intervenções que a contratransferência pode realizar no tratamento e da necessidade de manter esse sentimento então sob controle: 'Em minha opinião, portanto, não devemos abandonar a neutralidade para com o paciente, que adquirimos por manter controlada a contra-transferência" (Freud, 1915/1980, p. 214).

Dessa maneira o complexo de Édipo, conceito tão fundamental para Freud, tem seus primeiros estudos em função da transferência. Tudo o que é descoberto no complexo de Édipo coaduna com a teoria sobre a dinâmica da transferência. Daí Freud dizer que, na transferência, o analista é colocado no lugar de uma das imagos primordiais do indivíduo: imago paterna, imago fraterna, ou imago materna. E é mediante as relações estabelecidas entre o complexo de Édipo e a transferência, que são considerados os obstáculos e as vantagens que a transferência traz para o tratamento.

A transferência é ambivalente; ela abrange atitudes positivas (de afeição), bem como atitudes negativas (hostis) para com o analista que, via de regra, é colocado no lugar de um ou outro dos pais do paciente, de seu pai ou de sua mãe. (Freud, 1940/1980, p. 202, gr. do autor)

Ao mesmo tempo, esse autor considera ainda duas outras vantagens que a transferência traz. São elas: o analista, colocado no lugar das imagos parentais, tem a concessão do poder que o superego exerce sobre o ego do indivíduo (uma vez que os pais foram a origem do superego); o superego, representado pelo analista, tem no tratamento analítico a oportunidade de ter seus erros corrigidos. A respeito dessa afirmação, Freud adverte que o analista deve tomar cuidado para não se transformar numa espécie de modelo ou professor para o paciente.

\section{Além da repetição: A complexidade da castração e os destinos da transferência}

Em Além do princípio do prazer, Freud (1920/1980) amplia a noção de compulsão à repetição a partir do conceito, então formalmente introduzido, de pulsão de morte. Até esse período da obra do autor, era conhecido que a compulsão à repetição estava vinculada às pulsões recalcadas, cujas satisfações estavam invariavelmente ligadas ao princípio do prazer. Isto é, considerava-se uma compulsão de tentar satisfazer conteúdos pulsionais que originalmente produziam prazer (o desprazer vinculado a tais conteúdos só surgia em função do recalque). Nesse momento o autor nota que, contudo, existem experiências compulsivamente repetidas que desde o início excluem qualquer possibilidade de prazer. Nessa constatação explica-se que os sentimentos edípicos, cujos desapontamentos são vividos com grande sofrimento por parte da criança, são todos repetidos pelos pacientes na transferência sob a forma de uma compulsão: "Procuram ocasionar a interrupção do tratamento enquanto este ainda se acha incompleto; imaginam sentir-se desprezados mais uma vez, obrigam o médico a falar-lhes severamente e a tratálos friamente" (Freud, 1920/1980, p. 34).

A tese apresentada em Além do princípio do prazer diz que a compulsão à repetição é uma tentativa de elaboração das vivências traumáticas. Repetindo, o indivíduo busca sujeitar as excitações que de início sofreu passivamente. Tais excitações são potencialmente traumáticas quando rompem aquilo que Freud denomina escudo protetor contra estímulos. Além disso, através da compulsão à repetição o ego desenvolve a capacidade de reconhecer a iminência de novas situações traumáticas, cujo alerta é dado pela liberação da angústia. Dessa forma, a possibilidade da ocorrência de um trauma é restringida a um sinal. Em outras palavras, a angústia é um aviso com o intuito de que o psiquismo empreenda os meios adequados para impedir a efetivação de uma situação aflitiva.

Segundo tal raciocínio, a angústia sobrevem ao paciente a cada vez que as intervenções analíticas aproximam-se dos pontos traumáticos, nodais de sua doença. Nesses momentos, o paciente muitas vezes utiliza a transferência como forma de fuga do enfrentamento dos conteúdos de sua neurose. Dessa maneira, envolvido com seus sentimentos transferenciais o indivíduo busca não saber de seu inconsciente.

Em Inibiçoes, sintomas e ansiedade (1926/1980) Freud esclarece que a angústia, ao contrário do que supunha em seus primeiros escritos, não é simplesmente uma libido transformada pelo efeito do recalque, e sim uma reação do ego diante da iminência de situações de perigo. Segundo essa nova tese freudiana, o recalque é efetivado justamente para que o ego não sucumba aos perigos apontados através da angústia. Alertado pela a angústia, o indivíduo produz os sintomas necessários para que os conteúdos traumáticos sejam encobertos.

As situações traumáticas representam uma experiência de desamparo por parte do ego, em face de um acúmulo de excitação (de origem interna ou externa) com o qual não consegue lidar.

O perigos internos modificam-se com o período de vida, mas possuem uma característica comum, a saber, envolvem a separação ou perda de um objeto amado, ou uma perda de seu amor - uma perda ou separação que poderá de várias maneiras conduzir a um acúmulo de desejos insatisfeitos e dessa maneira a uma situação de desamparo. (Freud, 1926/1980, p. 99)

Tais perigos internos são discriminados por Freud: perigo do desamparo psíquico; perigo da perda do objeto; perigo de castração e perigo advindo do superego. Mas o autor aponta que é sempre o temor latente da castração que envolve todas essas situações de perigo, na medida em que elas se referem ao medo da perda de um objeto precioso. O próprio medo da morte é explicado nesses termos:

A castração pode ser retratada com base na experiência da perda diária das fezes que estão sendo separadas do corpo ou com base na perda do seio da mãe no desmame. Mas nada que se assemelhe à morte jamais pode ter sido experimentado ... Estou inclinado, portanto, a aderir o ponto de vista de que o medo da morte deve ser considerado análogo ao medo da castração, e que a situação à qual o 
ego está reagindo é de ser abandonado pelo superego protetor - os poderes do destino. (Freud, 1926/1980, p. 153)

Nessa obra de 1926, é possível entender que o complexo de castração deixa de ser restrito à fase fálica. Agora não se trata somente do medo de vir a ser castrado do menino, ou do complexo de inferioridade da menina (ambos descritos nos estudos sobre o complexo de Édipo).Os sentimentos assim delimitados são apenas fantasias privilegiadas para manifestar o medo da castração; fantasias com as quais Freud nunca deixa de escrever o roteiro de suas pesquisas.

A angústia da castração passa a referir-se às reações do indivíduo diante de suas perdas, as quais revelam sua condição de desamparo. Desamparo que é constituído pela incapacidade do aparelho psíquico de dominar adequadamente os estímulos. Segundo Inibiçôes, sintomas e ansiedade, a condição humana é indissoluvelmente ligada a esse fato. Assim, se o desamparo humano é uma condição insuperável e ele está intrinsecamente ligado ao complexo de castração, esse último também pode ser considerado indestrutível. E ele recebe uma ênfase acentuada na obra de Freud.

Mas como as fantasias de castração podem apresentar-se num adulto normal ?

algumas dessas situações de perigo conseguem sobreviver, alcançando épocas posteriores, e modificam seus determinantes de ansiedade a fim de atualizá-los ... por exemplo, um homem pode reter seu medo de castração à guisa de uma sifilidofobia, após ter vindo a saber que não é mais habitual castrar pessoas por se entregarem a seus desejos sexuais, mas que por outro lado, graves doenças podem sobrevir a qualquer um que se entrega a seus desejos. (Freud, 1926/1980, p. 172)

Em sua teoria sobre o complexo de Édipo, Freud estabelece que o complexo de castração é responsável pelo início e desfecho dos sentimentos edípicos, para mulheres e homens respectivamente. E pode-se pensar que o protesto contra a castração impõe dúvidas quanto à possibilidade de finalização do complexo de Édipo. Pois a castração, seja como precondição (no caso das mulheres) ou como punição (no caso dos meninos), parece levar a uma renúncia dos desejos edípicos e não a uma elaboração que realmente os dissolva.

Quando o complexo de castração aparece então correspondendo ao temor do desamparo, ele passa a ser concebido como o pivô da entrada e da saída do tratamento analítico. E a dificuldade, ou mesmo, a incapacidade de elaboração desse complexo começa a colocar em questão a possibilidade de término de um processo de análise.

De certa maneira essa lógica permanece fiel aos primeiros escritos de Freud, os quais estabelecem as relações entre o complexo de Édipo (e sua vinculação ao complexo de castração) e a dinâmica clínica.

Tais relações vêm salientar a importância do superego. Essa instância psíquica é chamada herdeira do complexo de Édipo: a criança, diante da impossibilidade de satisfazer seus sentimentos edípicos, realiza uma identificação com as figuras parentais. Assim, são internalizadas as proibições e críticas a tais sentimentos, o que explica a vigilia dos valores morais no psiquismo (cumpre notar a advertência de Freud de que a severidade do superego não tem uma relação direta com a severidade dos pais (Freud, 1930/1980).

Segundo Freud, o superego é responsável pela insistência da necessidade de punição através da doença, observada na clínica. Esse fato parece mostrar que o desejo do incesto nunca recebe absolvição suficiente. Com isso, faz-se necessária a questão sobre o que fazer com o superego na condução de uma análise. Pois, mesmo que ele receba uma nova configuração através da figura do analista (o que, como foi apontado, Freud vê como uma das vantagens da transferência), ele não perde os princípios que o caracterizam como instância psíquica. Princípios que, identificados com a formação de ideais e com as exigências morais, fundamentam o sentimento de culpa relacionado aos desejos recalcados.

Freud avalia que tal sentimento de culpa constitui uma das mais fortes resistências do paciente ao desenvolvimento completo do tratamento analítico. E não se trata simplesmente de uma resistência a recordar um conteúdo recalcado, mas de uma resistência à própria melhora do quadro clínico ou à extinção da doença.

As resistências dos pacientes a abandonarem seus sofrimentos, e, a presença persistente da angústia da castração durante a análise conduzem Freud a um sério questionamento sobre os êxitos de sua prática clínica. Ele escreve, em 1937, Análise terminável e interminável (1937/1980). Aqui, as descobertas clínicas não alimentam o orgulho do autor, mas o colocam diante dos limites de sua técnica.

Nesse artigo, Freud enumera os fatores envolvidos nos prognósticos de um tratamento analítico, quais sejam: a origem traumática ou constitucional da neurose (sendo aquela considerada mais suscetível aos efeitos da análise); as alterações do ego realizadas em virtude dos mecanismos de defesa; os conflitos com o superego; a atuação maior da pulsão de morte. Dentre todos esses fatores, o autor nota uma decisiva importância do fator quantitativo. Ou seja, é a magnitude dos instintos que determina a possibilidade de o fortalecimento do ego (obtido durante o processo analítico) ser capaz de dominar os conflitos psíquicos. Freud chega mesmo a admitir que a psicanálise teria, por muito tempo, negligenciado os fatores econômicos da doença em favor dos aspectos dinâmicos e topológicos.

E é pelo viés econômico que o complexo de castração é aqui abordado (vale lembrar que o aspecto econômico desse complexo já é ressaltado por Freud desde Inibiçoess, sintomas e ansiedade [1926/1980]). O temor da castração relaciona-se a uma quantidade de energia indomável a qualquer amadurecimento do ego, sendo então um limite para a eficácia do tratamento psicanalítico. Tal fonte de energia está além dos substratos psicológicos, alcançando o campo biológico diante do qual o autor se detém..

Freqüentemente temos a impressão de que o desejo de um pênis e o protesto masculino penetraram através de todos os estratos psicológicos e alcançaram o fundo, e que, assim, nossas atividades encontram um fim. Isso é provavelmente verdadeiro, já que, para o campo psíquico, o campo biológico desempenha realmente o papel 
de fundo subjacente. O repúdio da feminilidade pode ser nada mais do que um fato biológico, uma parte do grande enigma do sexo. Seria difícil dizer se e quando conseguimos êxito em dominar esse fator num tratamento analítico. Só podemos consolar-nos com a certeza de que demos à pessoa analisada todo incentivo possível para reexaminar e alterar sua atitude para com ele. (Freud, 1937/1980, p. 287)

O complexo de castração, que nesse texto freudiano é descrito em termos deuma valorização da masculinidade, mostra-se o ponto central de dificuldades para o manejo da transferência. Porque, em virtude de tal complexo, o homem teme uma atitude passiva perante outro homem; fato esse que o leva a recusar o mérito de seu restabelecimento ao médico. $\mathrm{E}$ a mulher é vítima de forte depressão quando convencida de que o tratamento não pode lhe proporcionar o órgão masculino, alvo de suas buscas edípicas; dessa forma, os efeitos terapêuticos da transferência são obstruídos pelo sentimento de frustração.

É interessante apontar que essas manifestações do complexo de castração, observadas na relação de transferência, retratam a posição de impasse dos complexos de Édipo masculino e feminino. No masculino, permanece a rivalidade com o pai; no feminino, persiste a frustração do desejo de obter um falo, denotando o que o autor denomina inveja do pênis.

Com isso, Freud constata que a oportunidade de reedição da cena edípica, via transferência, não é suficiente para abarcar um término satisfatório para o tratamento analítico. Pois, na transferência cristalizada em torno do complexo de Édipo, as interpretações do analista mostram-se insuficientes para modificar a economia dos instintos que há por trás dessas reivindicações de poder e proteção, as quais se manifestam como um repúdio à feminilidade.

\section{Transferência e final de análise}

Análise terminável e interminável, sem negar os resultados clínicos que incentivaram o percurso freudiano, coloca em discussão o alcance dos tratamentos analíticos. E é assim que pergunta: "...existe algo que se possa chamar de término de uma análise há alguma possibilidade de levar uma análise a tal término?” (Freud, 1937/1980, p. 250) Nesse ponto, o autor esclarece o que é considerado um final de análise: a supressão dos sintomas e ansiedades do paciente; a conscientização de material reprimido suficiente para evitar a repetição de um processo patológico; uma mudança a tal ponto no psiquismo do paciente que tornase impossível esperar novos efeitos do tratamento.

Esse artigo não fornece uma resposta definitiva à questão citada; ao contrário, parece desdobrá-la: é possível um final de análise sem que exista um dissolução da transferência? 'Tal desdobramento não é diretamente abordado por Freud. Contudo, ele aponta seus indícios, especialmente quando faz referência ao paciente descrito em História de uma neurose infantil(Freud, 1918/1980), cujo caso clínico é conhecido como o homem dos lobos:

Suas resistências definharam e, nesses últimos meses de tratamento, foi capaz de reproduzir todas as lembranças e descobrir todas as conexões que pareciam necessárias para compreender sua neurose primitiva e dominar a atual. Quando me deixou, em meados do verão de 1914 ... acreditei que sua cura fora radical e permanente. Numa nota de rodapé acrescentada em 1923 à história clínica desse paciente, já comunicara que eu estava enganado. Quando, por volta do fim da guerra ... tive que ajudá-lo a dominar uma parte da transferência que não fora resolvida. Isso foi realizado em alguns meses ... Quinze anos se passaram desde então sem que tenha sido refutada a verdade desse veredicto, mas certas reservas tornam-se necessárias ... Diversas vezes, porém, durante esse período, seu bom estado de saúde foi interrompido por crises de doença que só podiam ser interpretadas como ramificações de sua doença perene ... Algumas dessas crises ainda estavam relacionadas a partes residuais da transferência, e, onde isso assim acontecia, por efêmeras que fossem, apresentavam caráter distintamente paranóico. (Freud, $1937 / 198$, pp. 248-249, grifos nossos)

A respeito da discussão entre transferência e término do tratamento analítico, um outro alvo de Freud é a análise de Sándor Ferenczi. Sem fazer referência explícita à identidade do paciente, ele comenta que, nesse caso, após a supressão dos sintomas e o encerramento da análise, o médico (no caso, o próprio Freud) fora surpreendido pelas críticas do paciente. Essas acusavam-no de não ter fornecido ao paciente uma análise completa, a qual deveria ter levado em conta o fato de que o sentimento transferencial nunca pode ser exclusivamente positivo. Freud então se defende dizendo que não é prudente, ou vantajoso, o analista levantar as transferências negativas quando elas não são manifestas. Entretanto, os comentários do autor sobre tal tema parecem demonstrar que o manejo da transferência negativa nunca deixa de ser um ponto nevrálgico em sua teoria.

Provavelmente essa controvérsia em torno da transferência negativa leva Freud a insistir na necessidade de o analista ser, ele próprio, submetido à análise. Isso porque os mecanismos de defesa do analista podem impedi-lo de lidar adequadamente com a transferência, tanto positiva quanto negativa. Essa hipótese é reforçada quando, sobre esse assunto, é feita uma referência direta a Ferenczi, o especial delator da transferência negativa:

Em 1927, Ferenczi leu um instrutivo artigo sobre o problema da terminação das análises. Ele finda com a confortadora garantia de que 'a análise não é um processo sem fim, mas um processo que pode receber um fim natural, com perícia e paciência suficientes por parte do analista' ... Ferenczi demonstra ainda o importante ponto de que o êxito depende muito de o analista ter aprendido o suficiente de seus próprios 'erros e equívocos' e ter levado a melhor sobre 'os pontos fracos de sua própria personalidade'. Isso fornece um suplemento importante a nosso tema. (Freud, 1937/1980, p. 281)

Com esse pensamento, não somente as análises terapêuticas dos pacientes, mas também as análises dos analistas evocam a problemática envolvendo os términos dos tratamentos. Freud claramente afirma que todo o analista, a intervalos de aproximadamente cinco anos, deve submeter-se mais uma vez à análise. Isso, portanto, pode ser visto como um processo interminável.

Essas considerações levam à idéia de que Freud, ao não saber que rumos dar à transferência, não inclui em sua obra uma teoria suficiente sobre o final de análise. Esse dado da teoria freudiana é explicado, especialmente, pela sua impressão diante do complexo de castração. Pois ao declarar esse complexo (que, 
nas palavras do autor, é um repúdio à feminilidade) num lugar inatingível pela psicanálise (qual seja, os substratos biológicos referidos em Análise terminável e interminável), Freud não encontra outra alternativa a não ser vê-lo sendo repetido continuamente na transferência.

\section{Ultrapassando o rochedo da castração}

Embora este trabalho limite-se a uma breve investigação sobre a teoria freudiana da transferência, aqui ele faz uma rápida alusão às considerações do pensamento lacaniano, as quais visam justamente as relações entre a castração, a transferência e o final de análise.

Lacan, unindo as teses de Freud com as teorias da antropologia e da lingüística estruturais, diz que a castração é a transformação que a linguagem exerce sobre o corpo do indivíduo. Em outros termos, a castração é uma operação realizada pelo significante.

A identificação com os significantes produz uma divisão no sujeito, a qual tem como conseqüência a perda do gozo de um corpo total. Dessa maneira pode-se concluir que a castração passa sim pelo corpo, mas, ao contrário do que parece comunicar os textos de Freud, ela não é perda de virilidade. É perda de gozo. Uma perda que realiza justamente a sexuação do sujeito: ele é homem ou mulher, não pode ser total. E o que determina as posições masculina e feminina não é a anatomia, mas a forma como está estruturado o desejo.

Baseando-se nesse raciocínio, o autor diz que a castração é a perda de gozo que instala o desejo e que, por isso, ele situa-a num ponto central de sua teoria: "O caminho no qual tento colocá-los ... é o de ressituar, no coração do problema, a castração. Pois a castração é idêntica àquilo a que chamei a constituição do desejo como tal'(Lacan, 1991/1995, p. 288)

Levar o sujeito a perceber sua submissão à linguagem e a reavaliar suas identificações com os significantes mestres, é um ponto necessário do processo analítico. É o que Lacan denomina destituição subjetiva. Chegar a isso é alcançar o rochedo da castração.

Além da castração está o impossível que a análise presentifica: o gozo absoluto, gozo do corpo total. A análise mostra que esse é, estruturalmente, impossível. Nenhuma intervenção analítica pode fornecer um complemento para o ser que se dividiu pela linguagem. Nas palavras do autor, há sempre uma falta-a-ser.

Nesse ponto, vale notar que o falo é considerado justamente o signo dessa falta-a-ser. Isto é, ele é um produto dessa falta e só faz apontá-la uma vez que se situa exatamente em seu lugar . Logo, o falo não é complemento.

É na medida em que está advertido disso, que o analista pode operar com a instituição do que Lacan denomina sujeito suposto saber. De acordo com esse autor, a transferência é motor da análise quando o saber do analista constitui-se como suposição e não como certeza. Esse caminho é contrário à idéia de um analista detentor de poder, capaz de ensinar as saídas para o sujeito livrar-se da castração.
O paciente supõe que o analista saiba sobre seu sofrimento. E para obter esse saber ele tenta, num jogo de sedução imaginária, descobrir o que quer o analista. Dessa maneira, a transferência é um novo contexto para a colocação da pergunta que está na gênese do desejo humano: o que quer o Outro? É tentando respondê-la que o sujeito insere-se no mecanismo de identificações com os significantes que o estruturam. Segundo Lacan, a pergunta referente ao desejo do Outro pode funcionar como uma tirania superegóica para o sujeito. Logo, o analista não deve trabalhar no sentido de mantê-la.

Porém, o analista só não é seduzido pela demanda do paciente se, ele próprio, acedeu à sua falta-a-ser. Isto é, se ele sabe que é apenas um lugar, um Outro necessário às associações do paciente. Mas qual a ação do analista diante dessa falta-a-ser que ecoa da castração? Lacan comenta:

não há ação que transcenda definitivamente os efeitos do recalcado. Talvez se houver uma, no último termo, é no máximo aquela onde o sujeito como tal se dissolve, se eclipsa, e desaparece. É uma ação a propósito da qual nada há de dizível. (Lacan 1991/1995, p. 326)

Para o autor, o acesso ao indizível além da castração só é possível através da fantasia. A fantasia é o modo com que o sujeito tenta dar consistência àquilo que ele imagina ser $\mathrm{O}$ complemento de seu ser. Nela, o sujeito dividido pela castração posiciona-se na esperança de restituir o gozo perdido.

O sujeito resiste justamente à impossibilidade de restituição desse gozo. Por isso, o autor afirma que um final de análise consiste na travessia da fantasia. Atravessar a fantasia significa que o sujeito, de um lado, descola-se dos seus significantes mestres e, de outro, desloca o objeto (causa de seu desejo) da função de complemento possível para sua falta-a-ser.

E o que acontece com a transferência quando a fantasia é atravessada? O abandono da esperança de um complemento para o ser leva ao desaparecimento do amor transferencial. Em outras palavras, o encontro com o inominável além da castração aponta para a impossibilidade do gozo absoluto. E a partir disso, a resposta do analista não é mais esperada. Daí Lacan dizer que, no final de análise, há o encontro com a inconsistência do Outro. Portanto, Lacan entende que o final de análise exige o esgotamento da transferência, o qual, por sua vez, necessita que seja ultrapassado o limite da castração.

Se o temor da castração aponta para o temor do desamparo, ao término de uma análise o sujeito concorda com a ausência de garantias. Segundo esse autor, Freud teria se detido ante a autoridade paterna, conservando então o analista como garantia (nesse caso, garantia da interpretação dos sintomas) durante todo o processo de uma análise.

Cumpre advertir que essas considerações estão longe de apontar todos os fundamentos da teoria lacaniana sobre final de análise, transferência e castração. Elas apenas têm o intuito de observar como os dilemas da teoria freudiana alimentam o encaminhamento da psicanálise. 


\section{Conclusão}

Desde o início de sua prática clínica, Freud depara-se com a dinâmica da transferência. É preocupado com tal dinâmica que o autor começa o desvendamento do complexo de Édipo. A partir de então, a transferência e esse complexo são indissoluvelmente ligados: os destinos edípicos são similares aos destinos da transferência.

A força e a permanência dos avatares do superego e do complexo de castração levam à hipótese (apresentada por D'Avila Lourenço, 2000) de que a teoria freudiana não apresenta, de fato, uma teoria sobre o final do complexo de Édipo. Essa hipótese, unida às relações entre tal complexo e transferência, produz a idéia de que Freud também não formula uma teoria suficiente sobre o final do processo de transferência.

Segundo as constatações de Freud (1937/1980), durante todo o percurso do tratamento o analista permanece como o foco dos conteúdos edípicos. Essa permanência cria obstáculos, talvez intransponíveis, para o manejo da transferência. Sem uma finalização adequada dos sentimentos transferenciais, torna-se problemática a questão referente aos términos dos tratamentos analíticos.

Diante dessas considerações, este artigo conclui que a obra freudiana é capaz de apresentar, ou mesmo instituir, a gênese e as nuances da transferência em suas relações com o tratamento. O que fica obscuro, entretanto, é se pode haver um desenlace bem sucedido da transferência num suposto final de análise.

Tal conclusão não infere um fracasso de Freud em sua lida com as dinâmicas da transferência. Ao contrário, são os encontros com a dialética entre o possível e o impossível de sua clínica (isto é, entre as repetições incansáveis e aquilo que é passível de término, de modificações) que encaminham Freud aos avanços de suas produções teóricas.

O árduo e fascinante caminho de Freud dá as diretrizes para que a clínica psicanalítica seja sempre repensada e reinventada para acompanhar as trajetórias sinuosas do desejo.

Assim as diretrizes freudianas conduzem Lacan a ressaltar que, na análise, o desejo do sujeito só surge e é recriado através do desejo do analista e do desejo pelo analista. Esse autor elabora uma teoria sobre o final de análise, que implica justamente na travessia do rochedo da castração e na destituição do lugar de saber que o analista ocupa na transferência.

\section{Referências}

Breuer, J. \& Freud, S. (1980). Estudos sobre a histeria (V. Ribeiro, Trad.). Em J. Salomão (Org.), Edição standard brasileira de obras completas de Sigmund Freud (Vol. II). Rio de Janeiro: Imago. (Original publicado em 1895)

D’ Avila Lourenço, L. C. (2000). O complexo de Édipo, na teoria de Jacques Lacan. Dissertação de Mestrado não-publicada, Curso de Pós-Graduação em Filosofia e Metodologia das Ciências, Universidade Federal de São Carlos. São Carlos, SP.
Freud, S. (1980). Fragmento da análise de um caso de histeria (V. Ribeiro, Trad.). Em J. Salomão (Org.), Edição standard brasileira de obras completas de Sigmund Freud (Vol. VII, pp.5-127). Rio de Janeiro: Imago. (Original publicado em 1905)

Freud, S. (1980). A dinâmica da transferência (J. O. A. Abreu, Trad.). Em J. Salomão (Org.), Edição standard brasileira de obras completas de Sigmund Freud (Vol. XII, pp. 131-143). Rio de Janeiro: Imago. (Original publicado em 1912)

Freud, S. (1980). Recomendações aos médicos que exercem a psicanálise (J. O. A. Abreu, Trad.). Em J. Salomão (Org.), Edição standard brasileira de obras completas de Sigmund Freud (Vol. XII, pp. 147-159). Rio de Janeiro: Imago. (Original publicado em 1912)

Freud, S. (1980). Sobre o início do tratamento (Novas recomendações sobre a técnica da psicanálise I) (J. O. A. Abreu, Trad.). Em: J. Salomão (Org.), Edição standard brasileira de obras completas de Sigmund Freud (Vol. XII, pp. 163-187). Rio de Janeiro: Imago. (Original publicado em 1913)

Freud, S. (1980). A história do movimento psicanalítico (T. O. Brito, P. H. Britto \& C. M. Oiticica, Trad.). Em J. Salomão (Org.), Edição standard brasileira de obras completas de Sigmund Freud (Vol. XIV, pp. 13-82). Rio de Janeiro: Imago. (Original publicado em 1914)

Freud, S. (1980). Recordar, repetir e elaborar (J. O. A. Abreu, Trad.). Em J. Salomão (Org.), Edição standard brasileira de obras completas de Sigmund Freud (Vol. XII, pp. 191-203). Rio de Janeiro: Imago. (Original publicado em 1914)

Freud, S. (1980). Observações sobre o amor transferencial (Novas recomendações sobre a técnica da psicanálise III) (J. O. A. Abreu, Trad.). Em J. Salomão (Org.), Edição standard brasileira de obras completas de Sigmund Freud (Vol. XII, pp. 207221). Rio de Janeiro: Imago. (Original publicado em 1915)

Freud, S. (1980). História de uma neurose infantil (J. O. A. Abreu, Trad.). Em J. Salomão (Org.), Edição standard brasileira de obras completas de Sigmund Freud (Vol. XVII, pp. 19-152). Rio de Janeiro: Imago. (Original publicado em 1918)

Freud, S. (1980). Além do princípio do prazer (C. M. Oiticica, Trad.). Em J. Salomão (Org.), Edição standard brasileira de obras completas de Sigmund Freud (Vol. XVIII, pp. 17-89). Rio de Janeiro: Imago. (Original publicado em 1920)

Freud, S. (1980). A dissolução do complexo de Édipo (C. M. Oiticica, Trad.). Em J. Salomão (Org.), Edição standard brasileira de obras completas de Sigmund Freud (Vol. XIX, pp. 217-228). Rio de Janeiro: Imago. (Original publicado em 1924)

Freud, S. (1980). Inibições, sintomas e ansiedade (C. M. Oiticica, Trad.). Em J. Salomão (Org.), Edição standard brasileira de obras completas de Sigmund Freud (Vol. XX, pp. 95-203). Rio de Janeiro: Imago. (Original publicado em 1926)

Freud, S. (1980). O Mal-estar na civilização (J. O. A. Ribeiro, Trad.). Em J. Salomão (Org.), Edição standard brasileira de obras completas de Sigmund Freud (Vol. XXI, pp. 81-178). Rio de Janeiro: Imago. (Original publicado em 1930)

Freud, S. (1980). Análise terminável e interminável (J. O. A. Ribeiro, Trad.). Em J. Salomão (Org.), Edição standard brasileira de obras completas de Sigmund Freud (Vol. XXIII, pp.239-287). Rio de Janeiro: Imago. (Original publicado em 1937)

Freud, S. (1980). Esboço de Psicanálise (J. O. A. Abreu, Trad.). Em J. Salomão (Org.), Edição standard brasileira de obras completas de Sigmund Freud (Vol. XXIII, pp. 165-237). Rio de Janeiro: Imago. (Original publicado em 1940)

Garcia-Roza, L. A. (1994). Frende o inconsciente. Rio de Janeiro: Jorge Zahar. (Original publicado em 1984)

Lacan, J. (1995). O seminário, livro VIII: A transferência (1960-1961) (D. D. Estrada, Trad.). Rio de Janeiro: Jorge Zahar. (Original publicado em 1991)

Lacan, J. (1962-1963). Seminaire X, l'angoisse. Retirado em 25/09/2003, do site da Ecole Lacanienne de Psychanalyse, no World Wide Web: http:/ /www.ecole-lacanienne.net

Laurent, E. (2000)._As paixões do Ser. Salvador: Escola Brasileira de Psicanálise \& Instituto de Psicanálise da Bahia.

Nasio, J. -D. (1993). Cinco lições sobre a teoria de Jacques Lacan (V. Ribeiro, Trad.).Rio de Janeiro: Jorge Zahar. (Original publicado em 1992)

Quinet, A. (1995). As 4+1 condiçōes da análise. Rio de Janeiro: Jorge Zahar. (Original publicado em 1991)

Silvestre, M. (1991). Amanbã, a psicanálise (A. Roitman, Trad.). Rio de Janeiro: Jorge Zahar. (Original publicado em 1987)

Recebido: 22/07/2003

Última revisão: 18/12/2003

Aceite final: 21/01/2004

Sobre a autora

Lara Cristina d'Avila Lourenço é Psicóloga, Mestre em Filosofia e Metodologia das Ciências pela Universidade Federal de São Carlos, Doutoranda em Psicologia pela Universidade de São Paulo, Ribeirão Preto). É bolsista pela CAPES. 